\title{
Dust exposure and mortality in an American chrysotile textile plant
}

\author{
A D MCDONALD, ${ }^{1} \mathrm{~J}$ S FRY, ${ }^{1}$ A J WOOLLEY, ${ }^{2}$ AND J MCDONALD ${ }^{2}$
}

From the Department of Epidemiology, ${ }^{1}$ St Mary's Hospital Medical School, and the TUC Centenary institute of Occupational Health, ${ }^{2}$ London School of Hygiene and Tropical Medicine, London, UK

ABSTRACT Three parallel cohort studies of asbestos factory workers were undertaken to investigate the effects of mineral fibre type and industrial process on malignant mesothelioma, respiratory cancer, and asbestosis. This report describes the mortality of a cohort of 2543 men, defined as all those employed for at least a month from 1938 to 1958 in a textile plant in South Carolina in which chrysotile was the only type of asbestos used. Of these, 863 men (34\%) had died before 31 December 1977, one from malignant mesothelioma. Twenty one deaths were ascribed to asbestosis and 66 to cancer of the lung. Compared with the number expected from South Carolina, there was an excess of 30 deaths from respiratory cancer (ICD 160-164) in men 20 or more years after first employment (SMR 199.5). In men employed five years or more, no SMRs for this category rose above 300 . Individual exposures were estimated (in mpcf $\times$ years) from recorded environmental measurements. Life table analyses and "log-rank" (case-control) analyses both showed a steep linear exposure-response that was some 50 -fold greater at similar accumulated dust exposures than in Canadian chrysotile mining and milling. These findings agree closely with those from another study in this plant and confirm that mesothelioma is rarely associated with chrysotile exposure. Cigarette smoking habits did not greatly differ between the textile workers and the Canadian miners and millers. The far greater risk of lung cancer in the textile industry, if not attributable to other identified cocarcinogens, may be related to major differences in the size distribution of fibres in the submicroscopic range which are not detected by the usual fibre or particle counting procedures.

This study was planned in 1976 when it had become clear that there was a substantially lower risk of mesothelioma in workers employed in mining and milling chrysotile than in most other groups of asbestos workers. ${ }^{1}$ As workers employed in the manufacture or use of asbestos products are usually exposed to amphibole fibres in addition to chrysotile the difference could well have been due to fibre type, as suggested many years earlier by Wagner $e t$ $a l^{2}$ There remained the possibility, however, that, for chrysotile at least, the explanation might also be related to the industrial process, with lower risks at the point of production than in manufacturing or use when the fibres are probably much finer as a result of mechanical forces. The experimental work of Pott, Stanton, and others (see review by Stanton ${ }^{3}$ ),

Received 15 February 1983

Accepted 7 March 1983 had already underlined this possibility; however, direct epidemiological evidence based on factory workers exposed only to chrysotile was too scanty to settle the matter. Accordingly we identified three factories, the one described here which used only chrysotile for textile manufacture, another which used only chrysotile for friction products, and a third which used chrysotile, amosite, and crocidolite in textile and various other processes. So far as mesothelioma is concerned the salient findings have been published ${ }^{4}$; they showed that this tumour was much more common in workers exposed to amphiboles, only one case being identified among 2341 deaths in the employees working only with chrysotile compared with 18 cases among 1429 deaths in those who had worked with mixed fibres.

In the meantime the chrysotile textile factory dealt with in this report had also been investigated by Dement and colleagues of the US Public Health Service (NIOSH). ${ }^{56}$ Their results on exposure- 
response for respiratory cancer were striking, linear in form but with risk many fold higher than in chrysotile production. ${ }^{7}$ The importance of these findings and the need for their confirmation added significance to our own study, covering as it does a much larger cohort, followed over a longer period, with independently collected and analysed observations.

\section{Materials and methods}

\section{PROCESS}

The factory in question is located on the outskirts of a major Atlantic port in South Carolina. It began the manufacture of asbestos containing gaskets and packings in 1895 and introduced textile processes for the production of asbestos yarn and cloth in 1909. The factory moved to its present site in 1914 and the methods remained much the same until 1978 when an entirely new extrusion process for yarn production was introduced. During the period immediately before this change most of the older textile machinery was moved to another plant.

The type of fibre used for the main products has always been chrysotile, mainly from Canada but also Rhodesia. A small amount of imported crocidolite yarn (less than 2000 pounds a year) was used from the early 1950s until 1972. It was processed at one location, wet or lubricated with oil or graphite, to unite woven tape and braided packing. In the late 1950 s a very small amount of amosite was used experimentally in carding but this was soon abandoned. The textile process itself was traditional in nature. Raw chrysotile was brought in as crude or semiopened fibre and passed to the preparation department for cleaning, further opening, blending with other grades, and mixing with cotton. There followed the usual processes of carding, winding, and spinning to produce strong yarn. Some yarn was sold but most went for weaving into braided and unbraided cloth and tape, some of which was later rubberised. Asbestos waste was collected at each stage and returned to the preparation area for reuse.

\section{STUDY GROUP}

The cohort studied comprised all those men or women, black or white, ever employed for one calendar month or more, who met two criteria. They had to have been employed before 1 January 1959 and to have had a social security number and name that matched with data in the US Social Security Administration files. In this cohort, race (colour) had been recorded in the employment records. Social Security numbers were allocated in 1937 . The cohort could thus be considered in two groups, those already working before 1 January 1938 and those first employed on or after that date. A distifiption between these two groups was maintained in the analysis because of the unknown effect of the tive process of survival required by those who qualified for the first group. In the event only minor differences in outcome were apparent so, this paper, the results are combined.

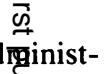

With help from the US Social Security Adrininist-
ation and additional local inquiries, we treed to ascertain the vital status of all members the cohort as of 31 December 1977. A search wis then made for death certificates from vital statistical departments of states and countries where death had occurred. The registered causes of death were.Zoded by a single qualified nosologist according $\overrightarrow{t \oplus}$ the seventh revision of the International Classifieation of Diseases (ICD). From a total of 2543 mes, 863 $(34 \%)$ are known to have died and certificate 3 were found in $827(95 \%)$; for the 1175 women, thes corresponding figures were lower, $160(14 \%)$ anj 147 $(92 \%)$. This paper will deal only with the 85 fmale $^{2}$ deaths of known age shown by age and cautse in table 1 . It may be noted that whereas the anafsis of Dement et $\mathbf{l}^{6}$ examined 26 deaths in white men ascribed to respiratory cancer (ICD 162-3), Call of which should be included in the present stuథy, we shall be considering 66 deaths (white and blac费) in a similar diagnostic group (ICD 162-4).

\section{EXPOSURE}

The information available to us on dust exposure was essentially the same as that used by Dentent $e t$ al-namely, over 5000 environmental Fomples taken since 1930 , mainly using the impinger method. The Metropolitan Life Insurance Company undertook five surveys from 1930 to $19 \$ 9$ and the United States Public Health Service two nक्ठre in 1968 and 1971 . The company had carried out 3 measurements from the 1930s and routinely from긱 956. In this paper we shall consider exposure estimated in dust particle concentrations and duration, and shall do no more than speculate in the discussion o\$possible equivalence in terms of fibre concentrotions. The environmental data were reviewed in de ail by the hygienist of our team (AJW) who alsosispent some time at the plant discussing past workin conditions with the older employees, includingosome who were responsible for the actual measurements. Each operation was considered separately and as fully as possible, noting changes in volume an fipractices of work, the introduction of ventilatiog and other control measures. Taking all this into acoount, and without reference either to health and mootality information or to the estimates made by Degूent, ${ }^{\circ}$ the dust concentrations prevailing for each jot, year by year, were assessed (see table 2). Thus we have 
Table 1 Male deaths by age and certified cause

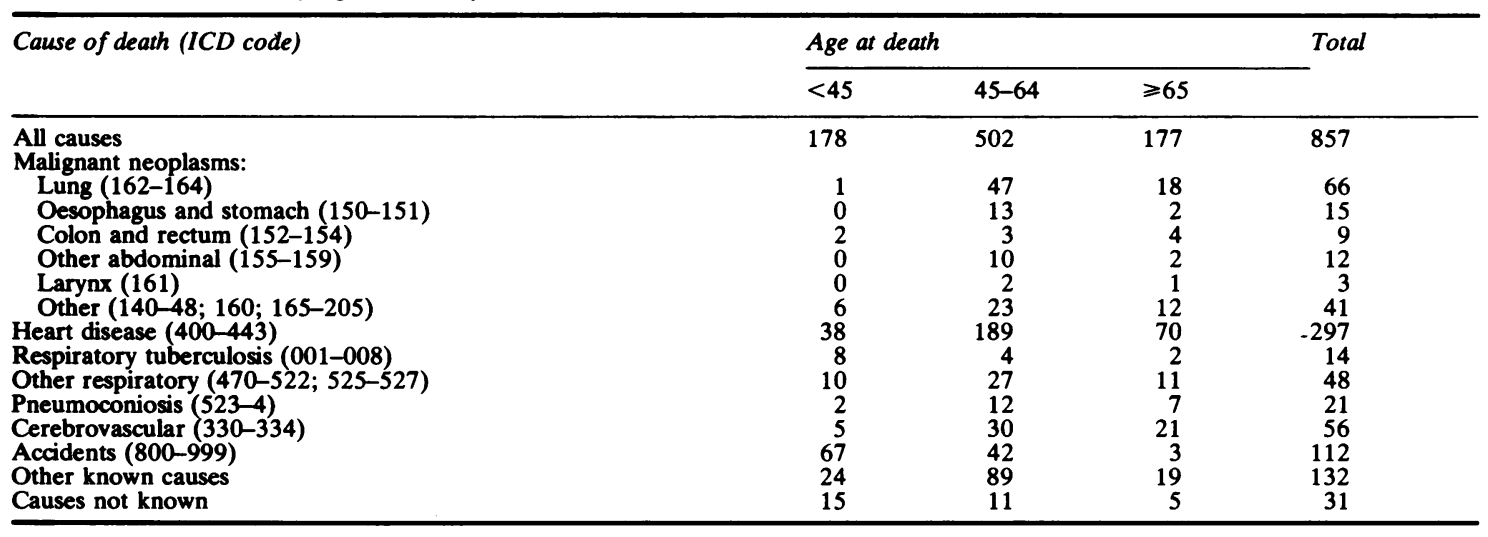

Table 2 Estimated average prevailing dust concentrations (mpcf) in main departments: 1930-70

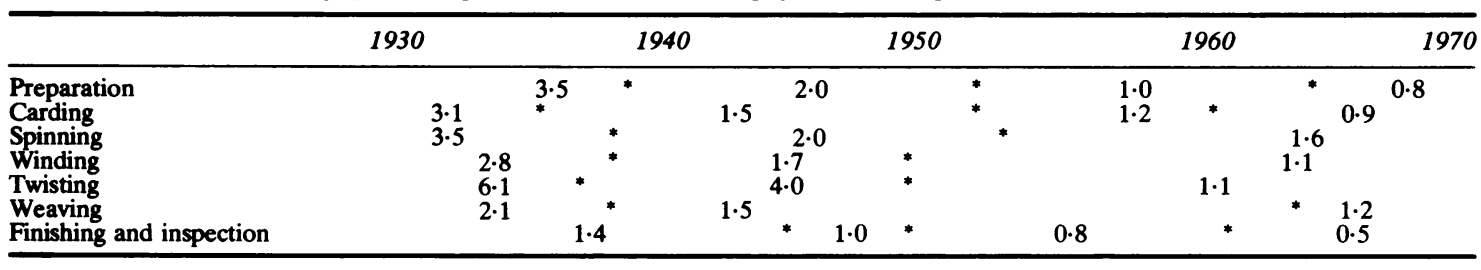

*Apparent improvement usually associated with technical change.

available for each man estimates of dust concentration in millions of particles per cubic foot (mpcf) and duration of exposure in years or fractions thereof $(y)$ expressed separately, or cumulatively (mpcf.y). This procedure was closely analogous to that followed in our studies of chrysotile miners and millers.

Among the many difficulties encountered in assessing historical exposure were work practices of much potential importance, also described by Dement, ${ }^{5}$ during the years 1937-53. In this period the dust filtration system (receiving dust from ventilation inflow in the preparation and carding departments) consisted of burlap bags stretched across wooden frames. Every day, the waste house operators would beat the bags with buggy whips to dislodge the accumulated dust. At the end of the week, the dust was shovelled into containers and returned to the preparation department for repro- cessing. This work and other clean up operations, which also entailed extremely high exposures, were carried out at weekends as optional overtime, foo which there was no shortage of volunteers. During the years 1945-64, another practice entailing very high exposure occurred in the preparation department. The mixing of fibres which, until that time, was subject to some degree of control was transferred to a mezzanine floor where asbestos was moved around by men with pitch forks without any form of dust suppression: these mezzanine and baghouse exposures, which could neither be assessed nor identified with individual workers, have not been included in any analysis, neither ours nor that of Dement $e t$ al.

With these reservations, the data available on exposure are summarised in table 3 grouped by duration of exposure. This shows that the average

Table 3 Age at start, duration of employment, and dust exposure (men only)

\begin{tabular}{|c|c|c|c|c|c|}
\hline & \multicolumn{5}{|c|}{ Length of gross service (years) } \\
\hline & $<1$ & $1,<5$ & $5,<20$ & $\geqslant 20$ & Total \\
\hline $\begin{array}{l}\text { No } \\
\text { Average age at start (years) } \\
\text { Gross service (years) } \\
\text { Net service (years) } \\
\text { Average dust concentration (mpcf) }\end{array}$ & $\begin{array}{l}950 \\
25 \cdot 6 \\
0 \cdot 39 \\
0 \cdot 37 \\
2 \cdot 11\end{array}$ & $\begin{array}{l}574 \\
25 \cdot 9 \\
2.43 \\
1.81 \\
1.86\end{array}$ & $\begin{array}{r}421 \\
26 \cdot 5 \\
10 \cdot 50 \\
7 \cdot 55 \\
1 \cdot 67\end{array}$ & $\begin{array}{l}465 \\
25 \cdot 2 \\
31 \cdot 86 \\
29 \cdot 51 \\
1 \cdot 23\end{array}$ & $\begin{array}{r}2410^{*} \\
25 \cdot 77 \\
8 \cdot 71 \\
7 \cdot 59 \\
1 \cdot 80\end{array}$ \\
\hline
\end{tabular}

*Excluding five whose employment histories were incomplete. 
age at start of work and the average dust concentration over the net years of employment were similar in all four duration groups.

\section{STATISTICAL ANALYYSIS}

The mortality and exposure data were analysed in two ways. The first followed the orthodox man-years life table approach of $\mathrm{Hill}^{\mathbf{8}}$ and others, whereby standardised mortality ratios (SMRs) are derived from comparison of observed numbers of deaths with numbers expected from mortality rates in a standard population. In this case age-, sex-, race (colour)-, year-specific rates for South Carolina were used. The second approach, essentially internal and case-control in type, followed the MantelHaenszel (or log rank) procedure, ${ }^{9}$ yielding relative risks from entirely intracohort comparisons. In calculating SMRs a "lag time" of 10 years before death (or end of 1977) was imposed in determining exposure, and only deaths 20 years or more from first employment were included. In the Mantel-
Haenszel analysis the same exclusions were applied, controls being selected from all other members of the cohort of the same sex and colour (black or white) who met the following criteria: (1) ali death of case, (2) same year of birth, if in orafter 1900 , or within five years if before 1900 , (3) within five years of date of first employment, befofe or after 1938. The statistical significance of differences between observed and expected numbers in this analysis and for departures from linearity werecalculated as $\chi^{2}$ values by the method of Petळand Pike. ${ }^{10}$ Lines were fitted to exposure-response results by Liddell using the method of Hanleyand Liddell (to be published).

\section{Results}

Table 4 summarises the mortality experience $\stackrel{\frac{\pi}{4}}{\text { the }}$ male cohort, based on the modified life table analysis. Overall, the SMR (all causes) is $27 \%$ above expectation and perhaps twice that in men emptoyed

Table 4 Male deaths 20 years after first employment, by cause, in relation to duration of service

\begin{tabular}{|c|c|c|c|c|c|c|c|c|c|c|}
\hline \multirow[t]{3}{*}{ Cause of death* } & \multicolumn{4}{|c|}{ Length of gross service (years) } & & & & & & $Z$ \\
\hline & \multicolumn{2}{|l|}{$<1$} & \multicolumn{2}{|c|}{$1,<5$} & \multicolumn{2}{|c|}{$5,<20$} & \multicolumn{2}{|l|}{$\geqslant 20$} & \multicolumn{2}{|c|}{ 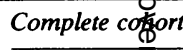 } \\
\hline & 0 & $S M R$ & 0 & $S M R$ & 0 & $S M R$ & 0 & $S M R$ & 0 & $S M R$ ఫ্ \\
\hline All causes & 159 & $107 \cdot 4$ & 113 & $122 \cdot 7$ & 120 & $156 \cdot 1$ & 178 & $136 \cdot 7$ & 570 & $127 \cdot 4$ 는 \\
\hline \multicolumn{11}{|l|}{ Malignant neoplasms: } \\
\hline Abdominal & 6 & 107.9 & 5 & $146 \cdot 4$ & 7 & $240 \cdot 3$ & 8 & 151.4 & 26 & 1510. \\
\hline Other & 12 & $130 \cdot 2$ & 7 & $124 \cdot 9$ & 9 & 195.9 & 7 & $46 \cdot 2$ & 35 & 12750 \\
\hline Heart disease & 69 & 108.9 & 34 & 87.6 & 45 & $141 \cdot 7$ & 70 & 120.8 & 218 & $116 \overline{7}$ \\
\hline Respiratory tuberculosis & 1 & $231 \cdot 8$ & 1 & 347.8 & 1 & 307.9 & 1 & $131 \cdot 5$ & 4 & $22 \overrightarrow{2 P} \leqq$ \\
\hline Other respiratory & 3 & $53 \cdot 3$ & 3 & 85.6 & 2 & $78 \cdot 3$ & 27 & 557.5 & 35 & $207 \cdot 3 \supseteq$ \\
\hline Pneumoconiosis & (0) & - & $(0)$ & - & $(0)$ & - & (20) & - & (20) & - O \\
\hline Cerebrovascular & 9 & $83 \cdot 0$ & 14 & 193.0 & 6 & $107 \cdot 3$ & 9 & $76 \cdot 2$ & 38 & $107 \cdot 2$ 음 \\
\hline Accidents & 18 & $121 \cdot 2$ & 8 & 89.7 & 5 & $75 \cdot 8$ & 9 & $85 \cdot 0$ & 40 & 97.0 \\
\hline Other known & 30 & 116.9 & 28 & $175 \cdot 5$ & 23 & $177 \cdot 7$ & 21 & $92 \cdot 3$ & 102 & $132 \cdot 4$ 으 \\
\hline Not known & 3 & & 3 & & 7 & & 0 & & 13 & $\overline{\bar{O}}$ \\
\hline
\end{tabular}

*As in table 1 except that ICD codes 160-164 are here grouped under "respiratory" malignant neoplasms and the "other respiratory" category includes only bronchitis, pneumonia, and pneumoconiosis (ICD 490-502, 523-4).

Table 5 Male deaths 20 years after first employment, by cause, in relation to dust exposure (mpcf.y) accumulated t 10 years before death

\begin{tabular}{|c|c|c|c|c|c|c|c|c|c|c|}
\hline \multirow[t]{3}{*}{ Cause of death* } & \multicolumn{10}{|c|}{ Dust exposure (mpcf.y) } \\
\hline & \multicolumn{2}{|c|}{$<10$} & \multicolumn{2}{|c|}{$10<20$} & \multicolumn{2}{|c|}{$20<40$} & \multicolumn{2}{|c|}{$40<80$} & \multicolumn{2}{|c|}{$\geqslant 80$} \\
\hline & $\overline{0}$ & $S M R$ & $\overline{0}$ & $S M R$ & 0 & $S M R$ & 0 & $S M R$ & 0 & $S M R \stackrel{ }{3}$ \\
\hline $\begin{array}{l}\text { All causes } \\
\text { Malignant neoplasms: } \\
\text { Respiratory } \\
\text { Abdominal } \\
\text { Other } \\
\text { Heart disease } \\
\text { Respiratory tuberculosis } \\
\text { Other respiratory: } \\
\text { Pneumoconiosis } \\
\text { Cerebrovascular } \\
\text { Accidents } \\
\text { Other known } \\
\text { Not known }\end{array}$ & $\begin{array}{r}31 \\
14 \\
28 \\
143 \\
3 \\
8 \\
(0) \\
29 \\
31 \\
79 \\
10\end{array}$ & $\begin{array}{r}143 \cdot 1 \\
114.9 \\
140.0 \\
103.5 \\
264.4 \\
65.9 \\
- \\
115.3 \\
99.2 \\
140.4\end{array}$ & $\begin{array}{r}5 \\
4 \\
3 \\
28 \\
0 \\
2 \\
(0) \\
2 \\
2 \\
9 \\
0\end{array}$ & $\begin{array}{r}182 \cdot 7 \\
231 \cdot 6 \\
109.2 \\
143.6 \\
-119.5 \\
- \\
50.0 \\
54.1 \\
116.9\end{array}$ & $\begin{array}{c}8 \\
4 \\
1 \\
29 \\
0 \\
6 \\
(3) \\
4 \\
5 \\
4 \\
2\end{array}$ & $\begin{array}{r}304 \cdot 2 \\
247 \cdot 0 \\
44 \cdot 9 \\
166 \cdot 6 \\
\overline{421} \\
\overline{12} \cdot 7 \\
124 \cdot 4 \\
630\end{array}$ & $\begin{array}{r}43 \\
7 \\
4 \\
0 \\
10 \\
1 \\
13 \\
(9) \\
2 \\
1 \\
5 \\
0\end{array}$ & $\begin{array}{r}419.5 \\
383.6 \\
-\quad \\
88.6 \\
634.4 \\
1407.8 \\
- \\
93.4 \\
49.4 \\
111.5\end{array}$ & $\begin{array}{c}33 \\
8 \\
0 \\
3 \\
8 \\
0 \\
6 \\
(8) \\
1 \\
1 \\
5 \\
1\end{array}$ & 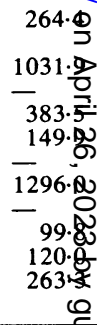 \\
\hline & & & & & & & & & & 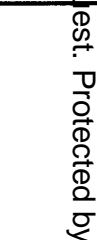 \\
\hline
\end{tabular}


Table 6 Dust exposure in male deaths from selected causes and controls (Mantel-Haenszel analysis ${ }^{2}$ )

\begin{tabular}{|c|c|c|c|c|c|c|c|}
\hline \multirow{2}{*}{ Linearity } & \multicolumn{5}{|c|}{$\begin{array}{l}\text { Dust exposure (mpcf.y) accumulated up to } 10 \text { years } \\
\text { before death of case }\end{array}$} & \multicolumn{2}{|l|}{ Chi square } \\
\hline & $<10$ & $10-19$ & $20-39$ & $40-79$ & $\geqslant 80$ & Difference & Linearity \\
\hline \multicolumn{8}{|c|}{ Pneumoconiosis (ICD 523) } \\
\hline Deaths & 0 & 0 & 3 & 10 & 4 & $17 \cdot 36$ & $10 \cdot 80$ \\
\hline Expected & $3 \cdot 1$ & $2 \cdot 2$ & $3 \cdot 8$ & $4 \cdot 1$ & $3 \cdot 7$ & & \\
\hline Relative risk & - & - & - & - & - & & \\
\hline \multicolumn{8}{|c|}{ Lung cancer (ICD 162-4): } \\
\hline Deaths & 25 & 3 & 8 & 7 & 6 & $24 \cdot 08$ & $20 \cdot 43$ \\
\hline Expected & $32 \cdot 4$ & $5 \cdot 4$ & $5 \cdot 3$ & $3 \cdot 7$ & $2 \cdot 2$ & & \\
\hline Relative risk & 1 & $0 \cdot 98$ & $2 \cdot 95$ & $4 \cdot 32$ & $15 \cdot 00$ & & \\
\hline \multicolumn{8}{|c|}{ Abdominal cancer (ICD 150-9): } \\
\hline Deaths & 13 & 4 & 2 & 4 & 0 & 4.06 & $2 \cdot 53$ \\
\hline Expected & $15 \cdot 5$ & $2 \cdot 9$ & $2 \cdot 5$ & $2 \cdot 1$ & 0 & & \\
\hline Relative risk & 1 & $1 \cdot 64$ & $1 \cdot 30$ & $7 \cdot 63$ & - & & \\
\hline \multicolumn{8}{|l|}{ All causes: } \\
\hline Deaths & 331 & 45 & 53 & 37 & 24 & $14 \cdot 42$ & $10 \cdot 63$ \\
\hline Expected & $348 \cdot 0$ & $46 \cdot 2$ & $48 \cdot 5$ & $32 \cdot 4$ & $15 \cdot 0$ & & \\
\hline Relative risk & 1 & 1.05 & 1.43 & $1 \cdot 51$ & $2 \cdot 17$ & & \\
\hline
\end{tabular}

five years or more. As there is $(a)$ a $7 \%$ excess even in men employed less than one year, unexplained by any asbestos related cause of death, and $(b)$ a $32 \%$ overall excess in deaths of "other known causes" the SMRs are probably somewhat inflated, mortality in South Carolina having presumably provided an imperfect basis for comparison. Much of the excess, however, is clearly attributable to respiratory cancer, pneumoconiosis, and gastrointestinal cancers. Table 5 shows the cohort mortality, related to dust exposure. There is a steady gradient from 115.5 to 264.4 for mortality (all causes) and a much steeper slope for respiratory cancer and also for selected other respiratory diseases (which include pneumoconiosis). No clear trend is apparent in the other diagnostic categories.

Table 6 shows the results of the a posteriori Mantel-Haenszel analysis for certain diagnostic groups only. The number of deaths included in this analysis falls short of those used in tables 4 and 5-for example, 490 compared with 570 from all causes; in the remainder no matching control could be found. There is clear confirmation of a statistically significant linear trend in lung cancer, pneumoconiosis, and deaths (all causes) but no convincing association for the abdominal cancers.

Only one death ascribed to mesothelioma was found-a man born in 1904 who died in 1967 . He was first employed at the plant in 1925, worked as a mule spinner from 1933 to 1955 and as an oven helper until he left in 1965. The tumour was stated to be peritoneal but there was no necropsy.

\section{Discussion}

The pattern of mortality in this cohort of chrysotile textile workers is similar to that reported for Quebeco chrysotile miners and millers, particularly those 0 employed at Thetford Mines. ${ }^{7}$ Overall, the SMRs? for the factory workers are somewhat higher than $z$ for the miners (perhaps due in part to questions of comparability with the reference populations). $\stackrel{\Phi}{3}$ There is the same scarcity of deaths attributed to mesothlioma and, in both cohorts, the relationship of lung cancer mortality to accumulated dust expos- $\vec{\oplus}$ ure is virtually linear. It is only when we examine thece actual levels of exposure that the astonishing diffes:ence between the experience of these two chrysot exposed cohorts is to be seen. This is illustrated in fig 1 where, to facilitate comparison, the SMRs in both\% cohorts are based on exposure accumulated to age 45 (see McDonald $e t a l^{7}$ ). In fact, the slope of the exposure-response line for lung cancer in the textile을

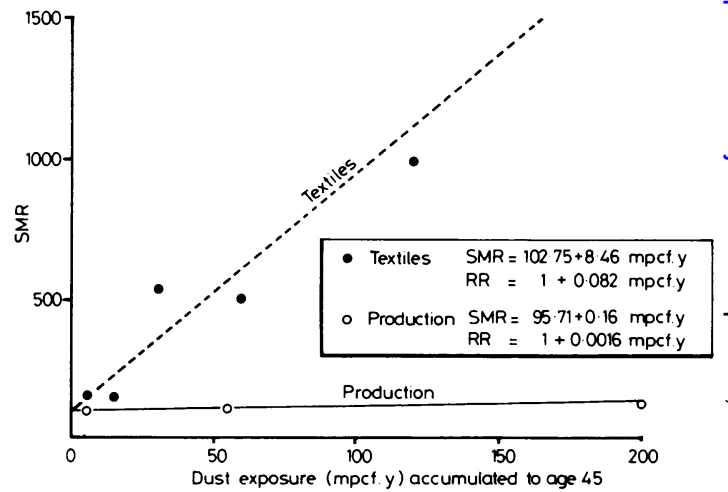

Fig 1 Respiratory cancer SMRs in relation to dust exposure accumulated to age 45 in chrysotile production and textile manufacture. 
workers is $\mathbf{5 0}$ times more steep than that observed in miners and millers. We thus confirm almost exactly the findings of Dement et al in their smaller cohort from the same plant ${ }^{6}$; the agreement is very close (see fig 2). The data shown in this graph are based on mortality for white men only, 15 years or more from first employment and therefore differ somewhat from the figures in table 5 .

The difference between fibre production and textile manufacture, if real, has important implications. ${ }^{20}$ The possibility of error must therefore be considered. Our data on mortality and those of Dement et al are independent but those on exposure are not. The dust concentrations, although extraordinarily low when compared with mining and milling were numerous, reasonably consistent among several groups of observers, and similar to levels recorded in the other American textile plant we have studied $^{4}{ }^{11}$ and probably also to the Rochdale textile plant, ${ }^{12}$ although there are technical difficulties in making the latter comparison. The concentrations were also in the same range as those recorded in an American asbestos friction products plant in which little or no excess lung cancer mortality occurred. ${ }^{421}$ These observations all raise questions of dust fibre conversion in these varied industries; this will be discussed below. In like manner, we must consider the possibility of error in the chrysotile mining and milling studies. In these there were far more environmental measurements, many made by our own team. ${ }^{13}$ So far as mortality was concerned, our findings were consistent at four different points over a nine year period ${ }^{14}$ and were essentially confirmed independently in a subcohort by Nicholson et al. ${ }^{15}$

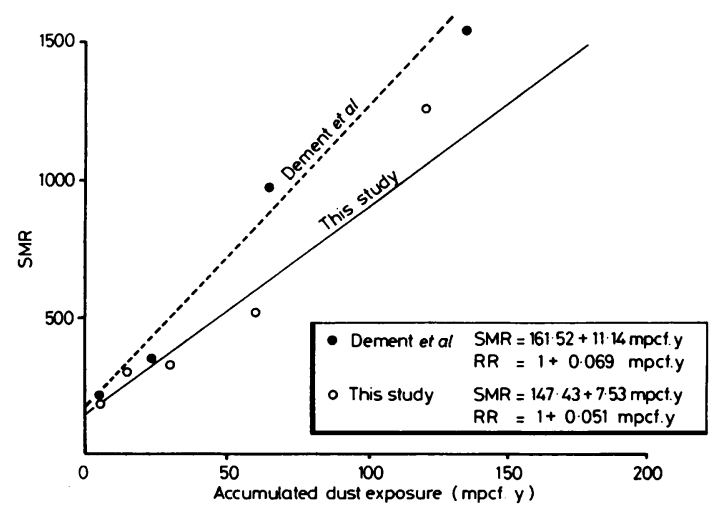

Fig 2 Respiratory cancer SMRs in white men 15 years or more from frst employment in relation to accumulated dust exposure. Comparison of this study and that of Dement et al. ${ }^{\circ}$
It thus seems that error per se can be dismissed, but there remain two other possibilities. The fist is that both Dement $e t$ al and we failed to give sufficient weight to the occasional extremely exposures that, from all accounts, many or most employees in the plant experienced during ove work "whipping the burlap" in the baghouse, 1937-53, and certain of them using pitch forks on

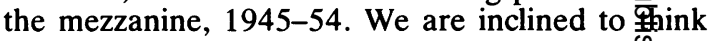
that these casual exposures, although significant, are unlikely to explain a more than twofold ermor in accumulated exposure estimates.

क

The second possibility concerns the fibre equivalence of impinger dust counts. This problem can be considered first at the level of equivalence of tibres more than $5 \mu$ in length per $\mathrm{ml}$, as counted on a membrane filter. In the mines and mills, conv\&rsion factors varied greatly ${ }^{1617}$ but, for lung cancer mortality, an average factor of 3.64 appeared to us appropriate. ${ }^{18}$ Nicholson accepted an earlier approximution of "about 3." 15 In the South Carolina textile क्ञlant Dement et al looked carefully at this questio $B$ and used a factor of 3 for all operations except preparation, where they used $8 .^{6}$ In a much earlier investigation by Ayer et al it was concluded that 6 might be appropriate for textile processes in that era. ${ }^{19}$ In our own review of the environmental measurements particularly during periods wherfboth dust and fibre concentration were assessedo we observed a range from $1 \cdot 3$ to $10 \cdot 0$, with an agrage of about 6 . These discrepancies are relatively min and it thus seems improbable that, even allowing for (a) substantial underestimation of the actual expossure experienced by the textile workers, (b) the rogghly twofold greater fibre equivalence in textiles then in mining and milling, and (c) some possible inflation of the SMRs resulting from use of the South Caळolina mortality rates, the 50-fold difference in exposure response can be reduced to less than about 10 胥old.

Of course, there remain other factors different in nature-for example, smoking habits or the pre्ठence of cocarcinogens. There is no convincing evideñce of the latter, although various oils were often used in the textile plant for spraying yarn during spinnting to prevent breakages. Only major differences in smoking habits could have much effect on the compatison between the textile and production workers? Our information on the question is fragmentary butoes not suggest that this was so. Dement et al presented a table which showed that, in 1965, the smoking habits of a sample of workers in their cohort-Were

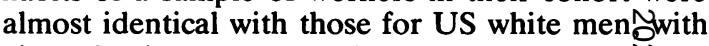
about $25 \%$ non-smokers. ${ }^{6}$ In October 1982 we्डsurveyed the smoking records of 553 currentrand recently retired employees at the plant and found that $171(31 \%)$ were non-smokers; however, \&f 246 
men born before 1930 (and therefore more representative of our cohort), $44(18 \%)$ were nonsmokers and there were indications that the proportion was lower still in the older men. Data on the Quebec mining cohort suggest that the proportion of non-smokers also varied with date of birth, falling from $25 \%$ in those born $1891-95$ to $9 \%$ in those born 1916-20. Once again, we find no major difference.

Thus we are left with two well established linear relationships between chrysotile dust exposure and risk of lung cancer, the one 50 times steeper than the other. Conversion from impinger particle counts to membrane filter fibre counts and underestimation of exposure might each halve the difference, and other possible sources of bias which have been discussed might reduce the difference further but hardly to less than 10-fold in all. That this may be the general situation as regards asbestos textile workers is supported by the results of the other cohort studies. ${ }^{11}{ }^{12}$ If cocarcinogens can be discounted the cause of the phenomenon must be in the nature of the chrysotile fibre exposure in these widely different industrial circumstances. Noting the experimental evidence in animals, we are led to speculate that the distribution of very fine fibres, seen only by electron microscope, may be different in the two situations. We have now embarked on research to test this hypothesis.

Many people and organisations helped with most aspects of this research. We thank especially Roslyn MacNish for coding causes of death and Sheryl Nixon for data processing. A grant toward the cost of the study was made to St Mary's Hospital Medical School by the Institute of Occupational and Environmental Health of the Quebec Asbestos Mining Association. Facilities for completing the study were afforded to Dr AD McDonald by the Institut de recherche en santé et en sécurité du Québec.

Reprint requests to: Dr JC McDonald, School of Occupational Health, McGill University, 1130 Pine Avenue West, Montreal, Canada H3A IA3.

\section{References}

' McDonald JC, McDonald AD. Epidemiology of mesothelioma from estimated incidence. Prev Med 1977;6:426-46.

${ }^{2}$ Wagner JC, Sleggs CA, Marchant $P$. Diffuse pleural mesothelioma and asbestos exposure in the North Western Cape Province. $B$ J Ind Med 1960;17:260-71.
${ }^{3}$ Stanton MF. Some etiological considerations of fibre car- $\underset{T}{\underline{T}}$ cinogenesis. In: Bogovski P, Gilson JC, Timbrell V, Wagner $C$ $\mathrm{JC}$, eds. Biological effects of asbestos. Lyon: International Agency for Research on Cancer, 1973:289-94. (IARC scientific publication No 8.)

${ }^{4}$ McDonald AD, Fry JS. Mesothelioma and fibre type in three American asbestos factories-preliminary report. Scand $J$ Work Environ Health 1982;8, suppl:53-8.

${ }^{5}$ Dement JM. Estimation of dose and evaluation of dose-response in a retrospective cohort mortality study of chrysotile asbestos textile workers. Chapel Hill: University of North Carolina, 1980. (Doctoral dissertation.)

- Dement JM, Hams RL, Symons MJ, Shy C. Estimates of dose response for respiratory cancer among chrysotile asbestos textile workers. Ann Occup Hyg 1982;26:869-87.

7 McDonald JC, Liddell FDK, Gibbs GW, Eyssen GE, McDonald AD. Dust exposure and mortality in chrysotile mining, 191075. Br J lnd Med 1980;37:11-24.

${ }^{8}$ Hill ID. Computing man years at risk. Br J Prev Soc Med 1972;26:132-4.

9 Mantel N, Haenszel W. Statistical aspects of the analysis of data from retrospective studies of disease. J Natl Cancer Inst 1959;22:719-48.

${ }^{10}$ Peto R, Pike MC. Conservatism of the approximation $\Sigma(0-E)^{2} / E$ in the log rank test for survival data or tumor incidence data. Biometrics 1973;29:579-84.

" McDonald AD, Fry JS, Woolley AJ, McDonald JC. Dust exposure and mortality in an American factory using chrysotile, amosite and crocidolite in mainly textile manufacture. $\mathrm{Br} J$ Ind Med 1983;40:368-74.

12 Peto $\mathrm{J}$. Lung cancer mortality in relation to measured dust levels in an asbestos textile factory. In: Wagner JC, ed. Biological effects of mineral fibres. Lyon: International Agency for Research on Cancer, 1980: 829-39. (IARC scientific publication No 30.)

${ }^{13}$ Gibbs GW, Lachance M. Dust exposure in the chrysotile mines $\overrightarrow{0}$ and mills of Quebec. Arch Environ Health 1972;24:189-97.

14 McDonald JC, Liddell FDK. Mortality in Canadian miners and $\omega$ millers exposed to chrysotile. Ann NY Acad Sci 1979;330: I 10.

is Nicholson WJ. Criteria document for Swedish occupational standards: asbestos and inorganic fibres. Vol 17. Stockholm: Arbete Och Hälsa, Vetenskaplig Skriftserie, 1981.

${ }^{16}$ Gibbs GW, Lachance M. Dust fibre relationships in the Quebec chrysotile industry. Arch Environ Health 1974;28:69-71.

17 Dagbert M. Etude de corrélation des mesures d'empoussiérage dans l'industrie de l'amiante. Document 5. Québec: Comité d'étude sur la salubrité dans l'industrie de l'amiante (président: René Beaudry, jcp) 1976.

${ }^{18}$ McDonald JC, Gibbs GW, Liddell FDK. Chrysotile fibre concentration and lung cancer mortality: a preliminary report. In: Wagner JC, ed. Biological effects of mineral fibres. Lyon: International Agency for Research on cancer, 1980:811-7. (IARC scientific publication No 30.)

${ }^{19}$ Ayer ME, Lynch JR, Farry JH. A comparison of impinger and membrane filter techniques for evaluating air samples in asbestos plants. Ann NY Acad Sci 1965;132:274-87.

${ }^{20}$ McDonald JC. Aspects of the asbestos standard. In: Gee JBL Morgan KC, Brooks SM, eds. Occupational lung disease. New York: Raven Press, 1983.

${ }^{21}$ McDonald AD, Fry JS, Woolley AJ, McDonald JC. Dust exposure and mortality in an American chrysotile friction products plant. $\mathrm{Br} J$ Ind $\mathrm{Med}$ (in press).

$$
\text { 然 }
$$
然 .

\section{.}

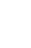
$\frac{10}{20}$ 